\title{
Neurosurgical management of a rare congenital supratentorial neurenteric cyst with associated nasal dermal sinus: case report
}

\author{
Paul MacMahon, MD, ${ }^{1,2}$ Stanca lacob, MD, PhD, ${ }^{2,5}$ Sarah E. Bach, MD, ${ }^{2-5}$ Eric T. Elwood, MD, $, 2,6$ \\ Julian J. Lin, MD, ${ }^{1,2}$ and Anthony M. Avellino, MD, MBA ${ }^{1,2,5}$ \\ Departments of ${ }^{1}$ Neurosurgery, ${ }^{3}$ Pathology, and ${ }^{6}$ Surgery, University of Illinois College of Medicine at Peoria; Departments \\ of ${ }^{2}$ Neurosurgery and ${ }^{5}$ Neurology, OSF Illinois Neurological Institute, OSF St. Francis Medical Center; and ${ }^{4}$ Department of \\ Neuropathology, Central Illinois Pathology, OSF St. Francis Medical Center, Peoria, Illinois
}

\begin{abstract}
The authors describe the case of a patient with the classic clinical presentation and radiographic features of a nasal dermal sinus with an associated intracranial cyst; however, histopathology revealed that the intracranial cyst was neurenteric instead of the typical epidermoid or dermoid cyst. Preoperative assessment included CT and MRI, which revealed a direct communication between the patient's nasal polypoid lesion and the anterior skull base via the foramen cecum. At the hands of a multidisciplinary plastic surgery and neurosurgery team, the patient underwent concurrent gross-total resection of the nasal polypoid lesion, the intracranial intradural cystic lesion, and their interconnecting tract.
\end{abstract}

https://thejns.org/doi/abs/10.3171/2017.7.PEDS17123

KEY WORDS neurenteric cyst; supratentorial; nasal dermal sinus; congenital

A NEURENTERIC or enterogenous cyst is an uncommon, benign congenital malformation that is most commonly located in the posterior mediastinum and is thought to result from displaced elements of the alimentary canal. Neurenteric cysts are rare in the CNS. However, when they do occur, the cysts are usually in the cervical or thoracic region and ventral to the spinal cord. ${ }^{3}$ Intracranial examples are even rarer, with most being in the posterior fossa. ${ }^{14-16}$ The intracranial etiology remains uncertain with the prevalent hypothesis suggesting that these cysts arise from dysgenesis of the neurenteric canal and foregut during notochord development, with retention of endoderm within the ectodermal layer., ${ }^{9,11}$

A nasal dermal sinus is a rare congenital malformation located within the midline in the frontonasal region. They are believed to be the most common congenital midline nasal mass and typically present in children as a small, firm, nonpulsatile, non-transilluminating mass located along the midline, anywhere between the glabella and nasal tip. While these entities may weep foul-smelling sebaceous material, most are asymptomatic. In some cases, these tracts may extend through the foramen cecum to involve the intracranial space, leaving the patient at increased risk of intracranial infections including abscess, meningitis, and osteomyelitis. ${ }^{17}$ If associated with a cyst, the cyst is epidermoid or dermoid. ${ }^{1,12}$ Classically, the diagnosis is made clinically, with craniofacial CT and MRI to investigate the degree of extension..$^{5,13}$

Herein, we describe the case of a patient with the classic clinical presentation and radiographic features of a nasal dermal sinus with an associated intracranial cyst; however, histopathology revealed that the intracranial cyst was neurenteric instead of the typical epidermoid or dermoid type.

\section{Case Report}

Clinical Presentation and Neuroimaging

A 3-year-old girl presented to our pediatric neurosurgery clinic with dysmorphic facial features. Upon assessment, the patient demonstrated hypertelorism, nasal hypoplasia, strabismus, and a 6-mm polypoid skin lesion at the base of the nasion along the midline (Fig. 1A). There was no evidence of developmental delay or reports of drainage from the patient's nasal polypoid lesion.

$\mathrm{CT}$ and MR imaging revealed a direct communication between the patient's nasal polypoid lesion and the anterior skull base through the foramen cecum (Fig. 2). At the termination of this tract and paracentral to the right of the 

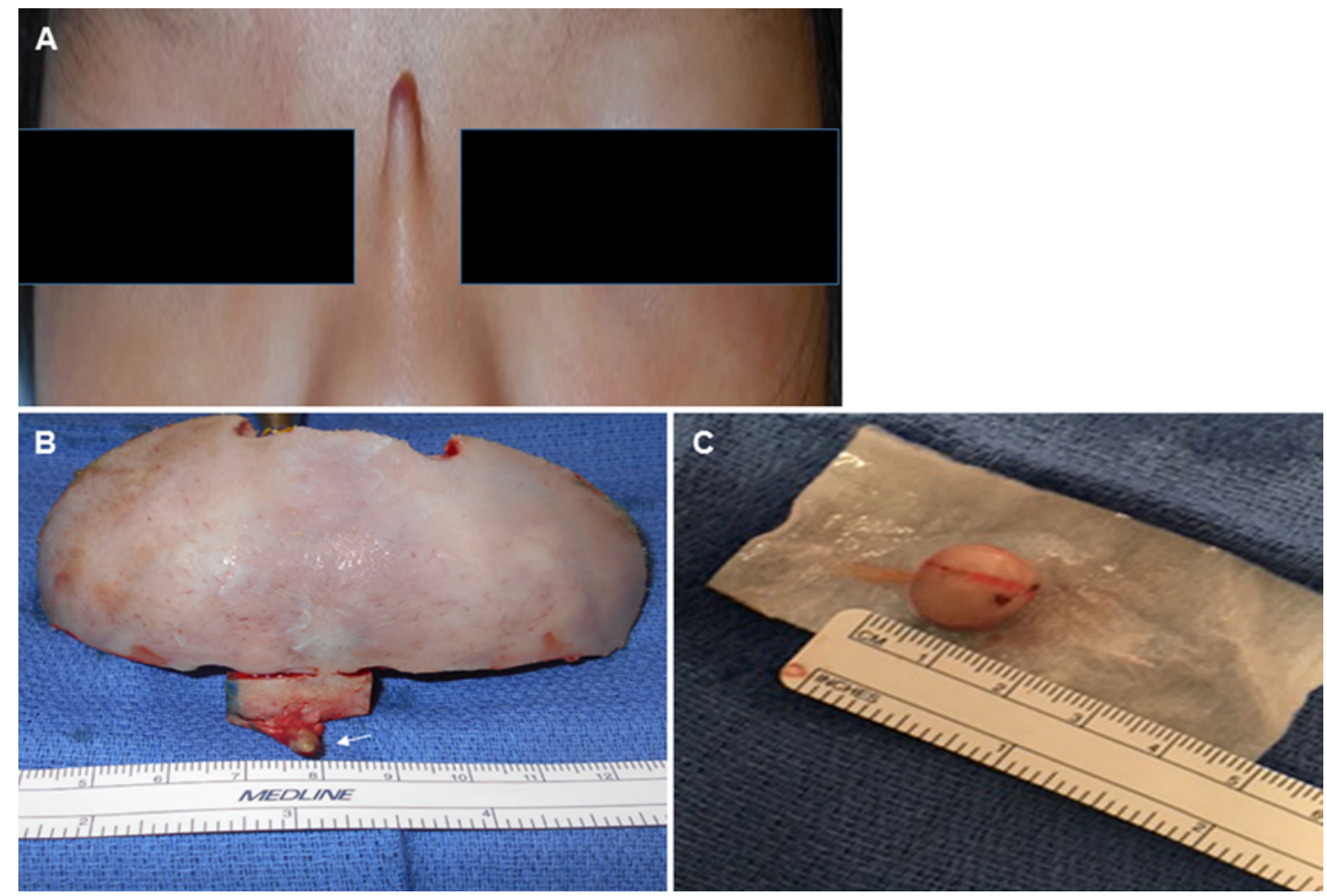

FIG. 1. Preoperative and intraoperative photographs of the cranial malformations, showing facial dysmorphism with a polypoid lesion localized at the nasion and hypertelorism (A [black bands obscure the patient's eyes]), the excised frontal cranial flap and attached polypoid (arrow, B), and gross pathology of the intracranial neurenteric cyst (C).

falx cerebri, a $1.3-\mathrm{cm}$ T1 hyperintense, T2 hypointense, nonenhancing cystic lesion was identified (Fig. 3A and B). Diffusion-weighted imaging demonstrated no restriction within this right parafalcine cystic mass (Fig. 3C). Given the location and imaging characteristics, this abnormality was felt to most likely represent a dermal sinus tract extending intracranially through the foramen cecum to an intracranial epidermoid, dermoid, or other cystic lesion (Fig. 3D and E). Neuroimaging studies revealed nearcomplete agenesis of the corpus callosum with an associated midline lipoma (Fig. 3F).

\section{Operation}

A multidisciplinary plastic surgery and neurosurgery team performed the surgery. The patient underwent concurrent resection of the nasal polypoid lesion, the intracranial intradural cystic lesion, and their interconnecting tract (Fig. 1B and C). Operatively, the patient underwent bicoronal subgaleal scalp elevation to the level of the nasofrontal junction. Following scalp flap elevation, the nasal portion of the tract was excised to the level of the frontal bone, at which time a bicoronal craniotomy was performed with the development of a keyhole osteotomy along the frontonasal region. An extensive bony keel along the anterior falx was found to be tightly adherent to the tract, but, after careful dissection, the nasal osteotomy containing both the extracranial and proximal intracranial tracts were removed en bloc. The distal intracranial tract was followed to the interhemispheric cyst, which was also removed en bloc, along with its falcine attachments (Fig. 1C). Finally, a periosteal flap was laid along the anterior skull base, and the nasion bone was reconstructed.

\section{Postoperative Course}

Postoperatively, the patient developed the syndrome of inappropriate antidiuretic hormone secretion and required hypertonic supplementation. These symptoms remitted, and the patient was discharged on postoperative Day 5 without further incident. Follow-up brain MRI performed at 9 months postoperatively revealed gross-total removal of the intracranial supratentorial cystic lesion and no change in the corpus callosum lipoma.

\section{Neuropathological Examination}

Microscopic examination of the sinus tract revealed portions of skin, fibrous tissue, cartilage, and bone. Within one fragment of fibrous tissue, there was a small focus of stratified squamous epithelium and the vague suggestion of this epithelium surrounding an occluded lumen (Fig. 4A), possibly representing the dermal sinus tract noted on imaging and intraoperatively. In addition, in a separate tissue fragment, there was a small hypercellular focus in the deep dermis/subcutaneous tissue (Fig. 4B). These cells were vaguely immunoreactive for epithelial membrane antigen (Fig. 4C), suggesting that they may represent meningothelial cells. This area was nonimmunoreactive for GFAP (Fig. 4D), indicating that there was no associated glial tissue. This small collection of probable meningothe- 

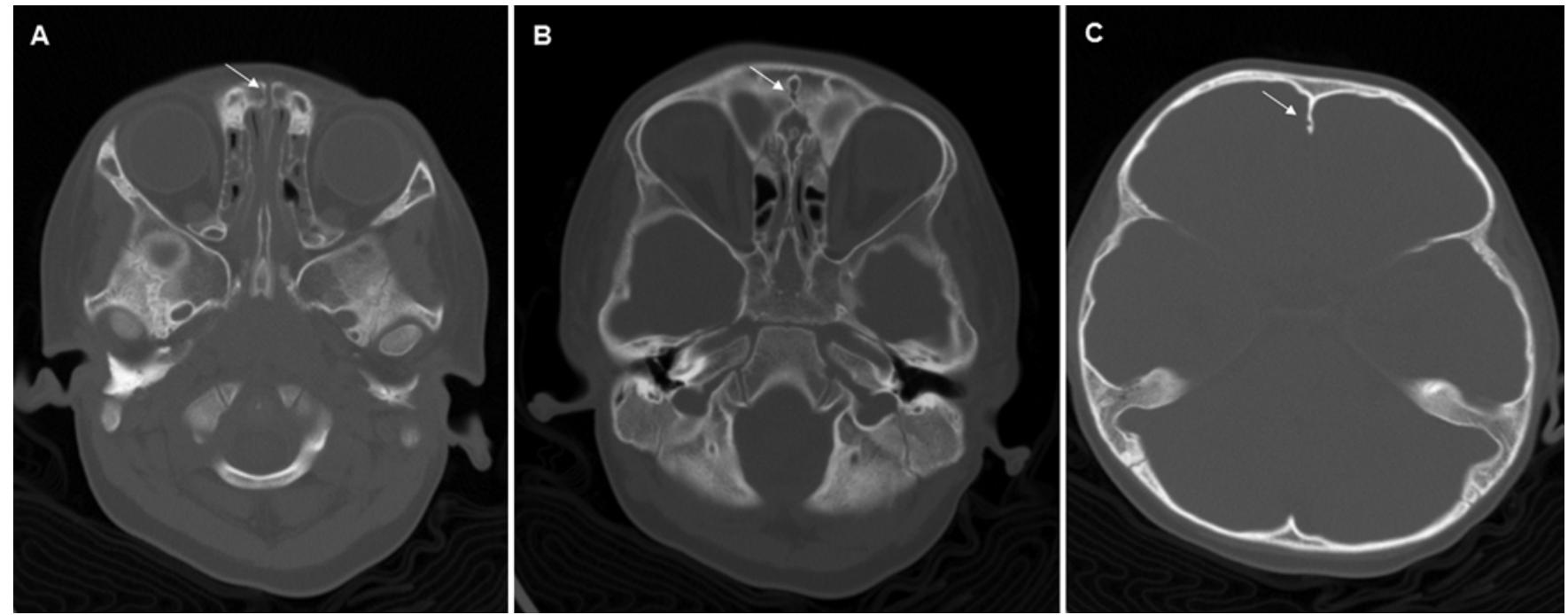

FIG. 2. Axial head CT scans showing a bony defect at the glabella (arrow, A) and extension of the defect into the foramen cecum (arrow, B) and midline bony septum (arrow, C).
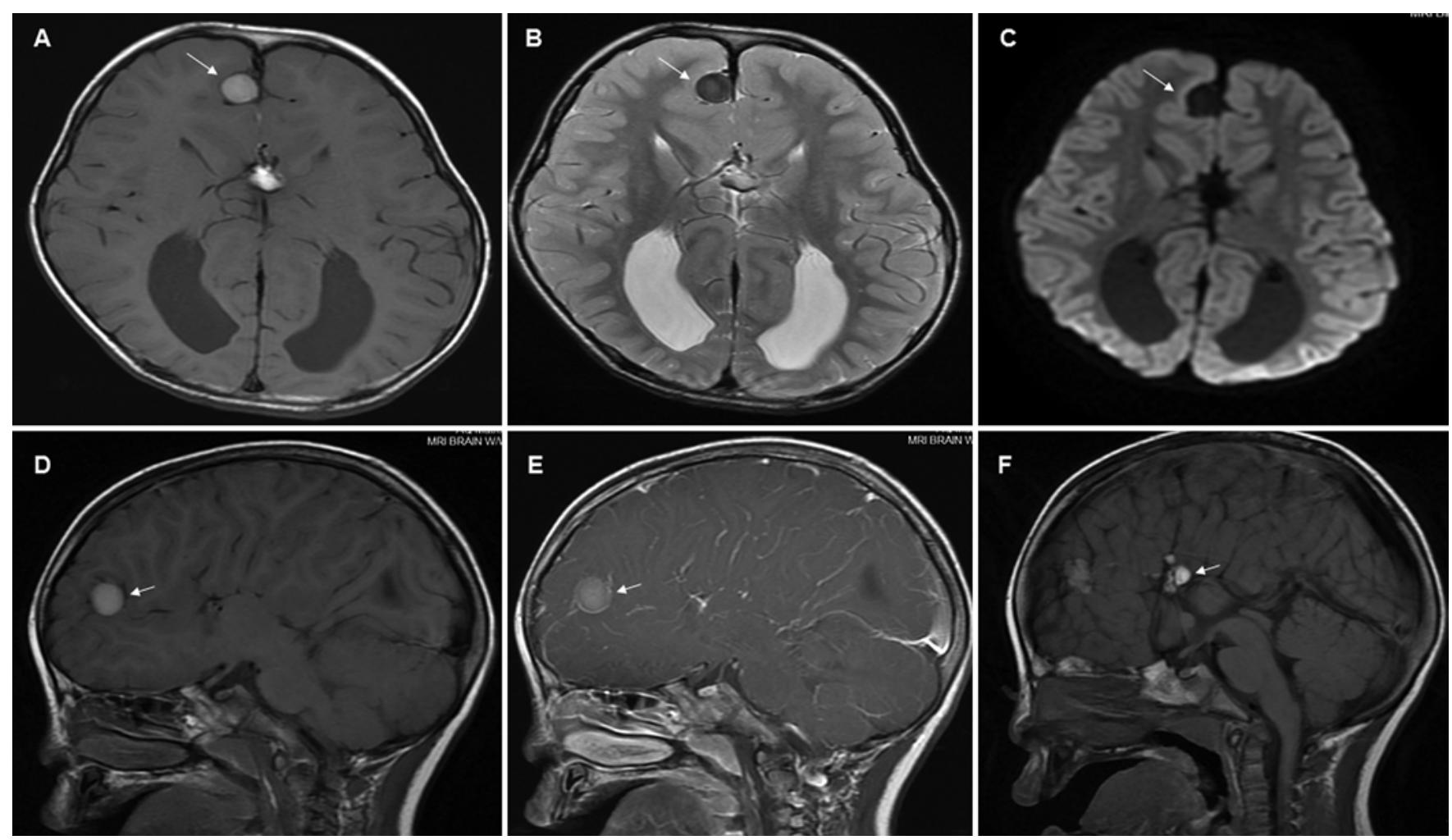

FIG. 3. A: Axial noncontrast T1-weighted MR image showing a nonenhancing right parafalcine extraaxial mass (arrow). B: Axial T2-weighted MR image showing a well-demarcated, hypointense, right parafalcine extraaxial mass (arrow). C: Axial diffusionweighted image showing lack of diffusion restriction within the right parafalcine extraaxial mass (arrow). D and E: Sagittal noncontrast (D) and with contrast (E) T1-weighted MR images showing the extraaxial mass (arrows). F: Sagittal noncontrast T1weighted MR image showing the near-complete agenesis of the corpus callosum with an associated midline lipoma (arrow).

lial cells may represent ectopic meningothelial tissue or possibly an atretic meningocele.

Microscopic examination of the interhemispheric cyst showed a cystic structure lined by simple columnar epithelium with numerous goblet cells, as well as scattered crypt or gland-like structures (Fig. 4E). A layer of smooth muscle was seen subjacent to the epithelium in some areas. This cyst epithelial lining and wall closely recapitulated colonic epithelium and mucosa. To confirm gastrointestinal differentiation, CDX2 (caudal-related homeodomain 

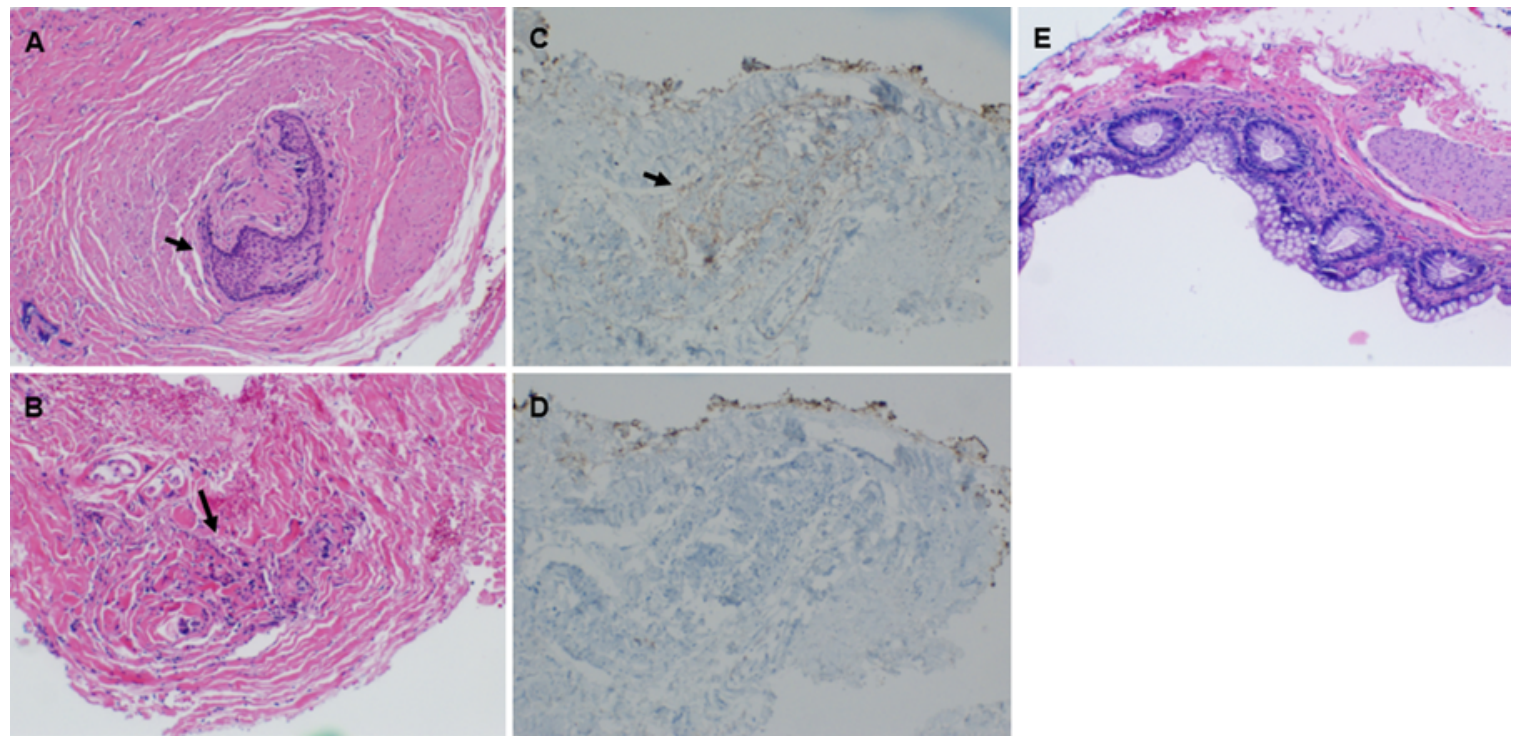

FIG. 4. A: Photomicrograph showing a fragment of fibrous tissue harboring a focus of stratified squamous epithelium with the vague suggestion of an occluded lumen (arrow), possibly representing the dermal sinus tract noted on imaging and intraoperatively. B: Within the dermis/subcutaneous tissue, a small hypercellular focus was identified (arrow). C: These cells were faintly immunoreactive for epithelial membrane antigen (arrow), suggesting that they may represent meningothelial cells. D: No glial tissue was seen in the area, as confirmed by negative GFAP immunostaining. This focus could be consistent with ectopic meningothelial tissue or possibly an atretic meningocele. E: A section of the cyst wall showed simple columnar epithelium with numerous goblet cells and crypts. Subjacent to the epithelium were a number of inflammatory cells and a layer of smooth muscle, reminiscent of the colonic lamina propria. $H \& E(A, B$, and $E)$. Original magnification (all panels) $\times 100$.

protein 2) expression was detected on immunohistochemical analysis, showing nuclear staining of intestinal cells (data not shown). The nuclear transcription factor CDX2 is a specific marker for intestinal epithelial cell differentiation and is expressed from the duodenum to cecum. A diagnosis of neurenteric cyst was rendered.

\section{Discussion}

\section{Pathophysiology}

Congenital malformations of the CNS encompass a spectrum of developmental anomalies of ectodermal, mesodermal, and/or endodermal origin. Congenital midline malformations are a subset of these lesions, with an estimated incidence of 1 in 20,000-40,000 births. ${ }^{18}$ The most common of these entities is the nasal dermal sinus, which is histologically composed of a tract lined with keratinizing squamous epithelium. Rarely, these lesions extend intracranially, placing the patient at increased risk of CNS infections and mandating resection.?

Traditionally, it is believed that this connection forms from a lack of separation of the dura mater from the nasal dermis along the prenasal space during gestation due to incomplete ossification of the frontal bone during the 2nd month of gestation. ${ }^{18}$ Classically, a nasal dermal sinus presents as an asymptomatic nasal polypoid lesion along the midline glabella region in children. In contrast, neurenteric cysts are rarely found in the CNS. Unlike a nasal dermal sinus, neurenteric cysts arise from the endoderm during embryogenesis and are composed of ciliated simple cuboidal or columnar epithelium with interspersed goblet cells. ${ }^{15}$ By and large, although much speculation ex- ists regarding the embryological pathogenesis of intracranial neurenteric cysts, no convincing hypothesis has been proposed or commonly accepted.

However, despite an obvious structural link between the supratentorial neurenteric cyst and the dermal sinus tract, we propose that these 2 lesions likely formed during distinct developmental stages of the brain and skull. We speculate that the neurenteric cyst formed early from dysgenesis of the neurenteric canal and foregut during notochord development, with retention of endoderm within the ectodermal layer during the 3rd and 4th weeks of development, ${ }^{6,9,11}$ while the dermal sinus tract formed later, during the 7th and 8th weeks of development due to the lack of midline bony fusion at the level of the foramen cecum. ${ }^{10}$

\section{Review of the Literature}

To our knowledge, there have been no previously reported cases of a midline, intradural, supratentorial neurenteric cyst with extracranial sinus extension through the foramen cecum in a manner closely resembling a classic nasal dermal sinus. Our detailed literature review did identify a small number of reported cases of supratentorial neurenteric cysts. ${ }^{2,11}$ In 2010, Mittal et al. published a review of such reports, citing 22 reported cases of intradural, supratentorial neurenteric cysts in patients ranging in age from 23 to 78 years. ${ }^{11}$ Of these cysts, none were associated with the midline frontonasal bone in association with an extracranial extension. Then, in 2011, Kurabe et al. reported the first case of a supratentorial, extradural endodermal cyst involving the left lateral frontal bone in an adult, but again, this was not associated with any extracranial anomalies. ${ }^{8}$ There has been one reported case 
of a nasal dermal sinus with dermoid cyst and associated colloid cyst of the third ventricle and another case of a nasal dermoid cyst with intracranial extension and an atretic dermal sinus tract. ${ }^{4,18}$

\section{Conclusions}

We describe the case of a patient with the classic clinical presentation and radiographic features of a nasal dermal sinus with an associated intracranial cyst; however, histopathological analysis revealed that the intracranial cyst was neurenteric instead of the typical epidermoid or dermoid type. Whether these 2 pathologies are embryologically related or merely coincidence is uncertain. Furthermore, even if the cyst were epidermoid or dermoid, we would suggest that there would be no significant differences in clinical behavior, since neurenteric, epidermoid, and dermoid cysts are all benign lesions. Preoperative assessment of the extra- and intracranial anatomy required CT and MRI. CT identified skull bone ossification defects, and MRI confirmed the extent of the extra- and intracranial malformation, without attachment to meninges or brain parenchyma. Due to the magnitude of the lesions, a grosstotal resection with an extra- and intracranial approach is recommended. From the limited amount of literature available, it appears that if one can achieve a gross-total resection of the dermal sinus tract and neurenteric cyst, the outcome is excellent, with no recurrence.

\section{References}

1. Brydon HL: Intracranial dermoid cysts with nasal dermal sinuses. Acta Neurochir (Wien) 118:185-188, 1992

2. Chakraborty S, Priamo F, Loven T, Li J, Insinga S, Schulder M: Supratentorial neurenteric cysts: case series and review of pathology, imaging, and clinical management. World Neurosurg 85:143-152, 2016

3. Chavda SV, Davies AM, Cassar-Pullicino VN: Enterogenous cysts of the central nervous system: a report of eight cases. Clin Radiol 36:245-251, 1985

4. Cheng ML, Chang SD, Pang D, Adler JR: Intracranial nasal dermoid sinus cyst associated with colloid cyst of the third ventricle. Case report and new concepts. Pediatr Neurosurg 31:201-206, 1999

5. Fornadley JA, Tami TA: The use of magnetic resonance imaging in the diagnosis of the nasal dermal sinus-cyst. Otolaryngol Head Neck Surg 101:397-398, 1989

6. Graziani N, Dufour H, Figarella-Branger D, Donnet A, Bouillot P, Grisoli F: Do the suprasellar neurenteric cyst, the Rathke cleft cyst and the colloid cyst constitute a same entity? Acta Neurochir (Wien) 133:174-180, 1995

7. Holzmann D, Huisman TA, Holzmann P, Stoeckli SJ: Surgical approaches for nasal dermal sinus cysts. Rhinology 45:31-35, 2007
8. Kurabe S, Okamoto K, Sasaki O, Fujii Y: Supratentrial extradural endodermal cyst involving the frontal bone. Acta Neurochir (Wien) 153:2493-2494, 2011

9. Little MW, Guilfoyle MR, Bulters DO, Scoffings DJ, O'Donovan DG, Kirkpatrick PJ: Neurenteric cyst of the anterior cranial fossa: case report and literature review. Acta Neurochir (Wien) 153:1519-1525, 2011

10. Marshall AL, Setty P, Hnatiuk M, Pieper DR: Repair of frontoethmoidal encephalocele in the Philippines: an account of 30 cases between 2008-2013. World Neurosurg 103:19-27, 2017

11. Mittal S, Petrecca K, Sabbagh AJ, Rayes M, Melançon D, Guiot MC, et al: Supratentorial neurenteric cysts-A fascinating entity of uncertain embryopathogenesis. Clin Neurol Neurosurg 112:89-97, 2010

12. Morimoto K, Takemoto O, Nishikawa M, Umegaki M, Nishino A: Nasal dermal sinus with a dermoid cyst. Pediatr Neurosurg 36:218-219, 2002

13. Osborn AG, Preece MT: Intracranial cysts: radiologicpathologic correlation and imaging approach. Radiology 239:650-664, 2006

14. Preece MT, Osborn AG, Chin SS, Smirniotopoulos JG: Intracranial neurenteric cysts: imaging and pathology spectrum. AJNR Am J Neuroradiol 27:1211-1216, 2006

15. Priamo FAI, Jimenez ED, Benardete EA: Posterior fossa neurenteric cysts can expand rapidly: case report. Skull Base Rep 1:115-123, 2011

16. Ray A, Chakraborty A, Donaldson-Hugh M: Enterogenous cyst of the posterior fossa. Br J Neurosurg 14:249-251, 2000

17. Shadravan I, Fishbein J, Hebert LJ: Streptococcal meningitis with an unusual port of entry. Am J Dis Child 130:214-215, 1976

18. Singh V, Sehrawat S, Kharat A, Kuber R: Nasal dermoid cyst with intracranial extension and an atretic dermal sinus tract. Med J Dr Y Patil Univ 5:47-50, 2012

\section{Disclosures}

The authors report no conflict of interest concerning the materials or methods used in this study or the findings specified in this paper.

\section{Author Contributions}

Conception and design: Avellino, MacMahon, Iacob, Bach. Acquisition of data: Avellino. Analysis and interpretation of data: Avellino, MacMahon, Bach, Elwood, Lin. Critically revising the article: all authors. Reviewed submitted version of manuscript: Avellino, Bach, Elwood, Lin. Approved the final version of the manuscript on behalf of all authors: Avellino.

\section{Correspondence}

Anthony M. Avellino, University of Illinois College of Medicine at Peoria, OSF Illinois Neurological Institute, $530 \mathrm{NE}$ Glen Oak Ave., Peoria, IL 61637. email: anthony.m.avellino@ osfhealthcare.org. 